\title{
Short-Term Functional Outcomes in Five Strand Hamstring Graft for Anterior Cruciate Ligament Reconstruction among Young Adults - A Prospective Pilot Study
}

\author{
Authors \\ Dr Sumit Kumar Goyal ${ }^{1}$, Dr Navin Kumar ${ }^{2 *}$, Dr Gopisankar Balaji ${ }^{3}$, \\ Dr Jagdish Menon ${ }^{4}$, Dr Sandeep Nema ${ }^{5}$, Dr J. Mohanakrishnan ${ }^{6}$ \\ ${ }^{1}$ Junior Resident MS (Orthopedics), Department of Orthopedics, JIPMER, Puducherry \\ ${ }^{2}$ Additional Professor and Head, Department of Physical Medicine and Rehabilitation (PMR), JIPMER, \\ Puducherry \\ ${ }^{3}$ Additional Professor and Head, Department of Orthopedics, JIPMER, Puducherry \\ ${ }^{4}$ Professor, Department of Orthopedics, JIPMER, Puducherry \\ ${ }^{5}$ Additional Professor, Department of Orthopedics, JIPMER, Puducherry \\ ${ }^{6}$ Junior Physiotherapist, Department of PMR, JIPMER, Puducherry \\ *Corresponding Author
}

\section{Dr Navin Kumar}

Additional Professor and Head, Department of PMR, PMRC Block, JIPMER, Puducherry -605006, India

Abstract
Anterior Cruciate Ligament (ACL) injuries are common sports injuries and ACL doesn't have healing
property. So, it is repaired by graft surgery. This pilot study assess the short-term functional outcomes
among young adults undergoing five strand Hamstring graft for anterior cruciate ligament injury using
IKDC score. A total of 14 patients were included in the study and were followed up for 6 months post
ACL reconstruction. The ACL injuries are more common in physically active age group of 20 to 40 years.
We found that pre-operative Mean IKDC scores were $43.22+/-9.91$. IKDC scores at 6 months follow up
were improved to $92.6+-1.85$ with significant differences ( $p$ - value $<0.001)$. There was improvement in
Pain Visual Analog score (VAS) from mean pre-operative VAS score was with standard deviation 1.21 to
post-operative VAS score 1.07 with standard deviation 1.49 (p value $<0.0001)$. The results of this study
can be used to plan a bigger study with a large sample size and extended follow-up.
Keywords: ACL injuries, reconstruction, five-strand hamstring graft.

\section{Introduction}

ACL injuries are most commonly associated with sports-related trauma. Injured ACL don't have healing property so it has to be replaced by other grafts. Many grafts are available for ACL reconstruction. Different surgeons proposed different techniques for preparing five strand hamstring graft and different fixation methods were used for five strand hamstring graft fixation in the tibial and femoral tunnel. In this current study, we used Bioscrew /Endobutton for femoral fixation and Bioscrew /Cortical screw+ washer for tibial fixation. 
Table-1: Comparison of different fixation methods in different surgical techniques

\begin{tabular}{|l|c|c|c|}
\hline Study & Femoral fixation & Tibial fixation & Graft \\
\hline Lee et al.[1] & femoral cortical button & tibial interference screw & $3 \mathrm{ST}+2 \mathrm{G}$ \\
\hline Prodromoset al.[2] & cancellous screw & cortical screw & $3 \mathrm{ST}+2 \mathrm{G}$ \\
\hline Laveryet al.[3] & EndoButton & screw & $3 \mathrm{ST}+2 \mathrm{G}$ \\
\hline Calvo et al.[4] & Tight Rope (Arthrex) & interference screw & $3 \mathrm{ST}+2 \mathrm{G}$ \\
\hline Tutkuset al.[5] & $\begin{array}{c}\text { absorbable interference } \\
\text { screws }\end{array}$ & $\begin{array}{c}\text { absorbable interference } \\
\text { screws }\end{array}$ & $3 \mathrm{ST}+2 \mathrm{G}$ \\
\hline Present study & Bioscrew /Endobutton & $\begin{array}{c}\text { Bioscrew /Cortical } \\
\text { screw+ washer }\end{array}$ & $3 \mathrm{ST}+2 \mathrm{G}$ \\
\hline
\end{tabular}

Patellar tendon and the hamstring grafts are among the most commonly used grafts for ACL reconstruction. Recently hamstring grafts got attention due to lack of comorbidities. But failure rate varies according to graft diameter. Usually, four-strand hamstring graft is used for ACL reconstruction but the revision surgery rate is high due to less graft diameter. To overcome this problem five strand hamstring graft can be used, the extra strand used increases graft diameter by $1-1.5 \mathrm{~mm}$.

This study was conducted for assessment of functional outcomes at short- term follow up in ACL reconstruction by five strand hamstring autograft in the young population and to study the associated comorbidities with hamstring graft.

\section{Aims and Objectives}

To assess the short-term functional outcomes among young adults undergoing five strand Hamstring graft for anterior cruciate ligament injury using IKDC and Lysholmscores.

\section{Materials and Methods}

We studied 14 patients, in which ACL reconstruction was done by five strand hamstring graft. All patients were subjected to a standardized surgical technique and post-operative rehabilitation protocol and followed up till 6 months post-operatively. Post-operative follow up included IKDC scores, Lysholm scores, anterior laxity, VAS score and $1 \mathrm{RM}$ max for hamstring muscle was documented and compared with preoperative scores.

Study Site: The study was carried out in the Orthopaedics department, JIPMER, Pondicherry, India.
Study Design: A Prospective cohort study.

Sample size: 14 patients

Study Duration: 24 months

Treatment follow up period: 6 months Eligibility for the study

Inclusion Criteria

1. Patients with symptomatic ACL deficient knee undergoing arthroscopically assisted ACL reconstruction due to instability within one year from the time of injury.

2. Age 18-45year

3. Normal contra lateral knee

\section{Exclusion Criteria}

1. Patients having associated PCL rupture.

2. Prior knee surgery/infection.

3. Avulsion fracture

4. Grade 3 collateral ligament injury/ meniscal tear involving $\geq 2 / 3^{\text {rd }}$ of meniscus

5. $\geq$ Grade 2 Kellegren-Lawrence arthritis

\section{Methodology}

This was a Prospective cohort study done on ACL deficient knee patients from July 2015 to December 2017 in the Department of Orthopaedics, JIPMER, Puducherry. The Institutes Ethical Committee and Post-graduate research monitoring Committee approved the study. A total of 14 patients were included in the study, all patients were operated with five- strand hamstring autograft. These patients were followed-up for 6 months.

Operative Method: ACL reconstruction was performed with the anatomical single-bundle technique. A $4 \mathrm{~cm}$ incision anteromedially on the tibia was made directly over the pes anserinus in line with the hamstring tendons. After the 


\section{JMSCR Vol||09||Issue||06||Page 55-62||June}

sartorius expansion has been identified, a longitudinal incision was made in Sartorius fascia to identified gracilis and semitendinosus tendons at their distal insertion on the anterior aspect of the tibia and tagged prior to harvest. All softtissue adhesions from each tendon were carefully removed before it is harvested. A tendon harvester was placed around the distal end of the tendon and was advanced along its substance into the proximal portion of the thigh. Gentle counter traction was applied to the distal end of the tendon with use of an angled retractor or clamp. When the harvester was advanced past the muscle-tendon junction, the tendon releases proximally and then pulled out of the harvesting device and out of the tibial incision. The tendons on the graft preparation table and cleaned of soft tissues, the length and the feasibility of tripling the semitendinosus were assessed and was converted in the triple layer with each strand in same tension. The gracilis was doubled and was kept over three strand of semitendinosus. We used a no 5 Ethibond suture to stitch all five strands at distal third part of hamstring autograft. In order to minimize bulk, we did Whip stitching in a nonlocked pattern.

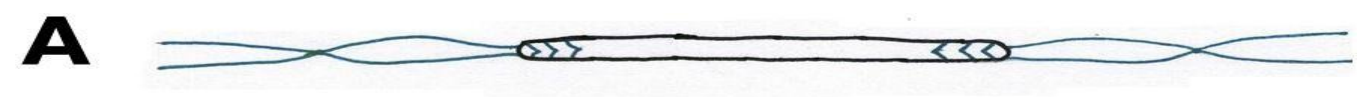

$\mathbf{B}$
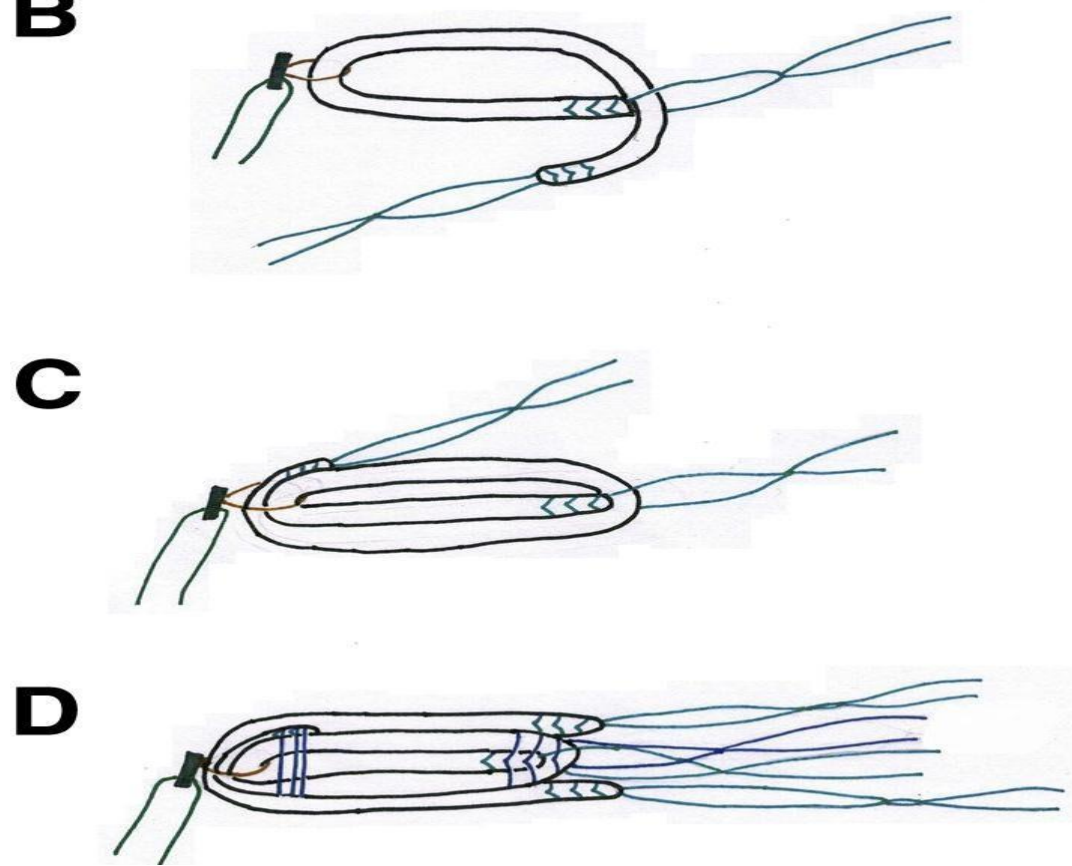

Fig 1 showing the 5-strand hamstring autograft technique. (A) ST graft is prepared at both ends with suture. (B) ST graft is tripled over itself. (C) A total of $5 \mathrm{~mm}$ of the thinner end of the ST graft is passed over the tripled graft (D) Final 5-strand graft with doubled gracilis graft on the top.

\section{Post op care}

The knee was immobilized in above knee POP slab. Post-operative day 2 the POP was discarded, and a small dressing and Bandaid used to cover the wounds and port sites. Drain removed and antibiotics stopped. Check x-ray was taken on post-operative day2.The knee was then put on a hinged knee brace or a posterior splint, and knee mobilization as per standard protocol (Appendix 6) was initiated. Simultaneously partial weight bearing was initiated with the help of axillary crutches. The target was $90^{\circ}$ knee flexion within 2 weeks and full flexion within 4-6 weeks. On the 14th-day stitch, removal was done. Crutches were 


\section{JMSCR Vol||09||Issue||06||Page 55-62||June}

used till $\sim 4$ weeks. Weaning off brace was achieved at 4-6 weeks by this time ligamentisation of the autografts starts. At 6 months post-operative IKDC, LYSHOLM score, anterior laxity,1 RM MAX for hamstring muscle strength, Visual Analog Scale (VAS) score was recorded and donor site morbidity waschecked.1 RM MAX was checked with the patient in prone position on leg curlmachine.

Statistical Analysis: The analysis was done by SPSS version 19 (IBM Inc, Chicago IL, USA) software. We presented data mean \pm SD. Paired student test was used to analyze the primary outcome measures (Differences in the scores) before and after the operation. We kept the level of significance at $5 \%$. We considered $\mathrm{P}$ value less than 0.05 as significant.

\section{Results}

In this study, 12 patients $(85.8 \%)$ were in age group of $20-40$ years, 1 patient $(7.1 \%)$ was less than 20 years of age and 1 patient $(7.1 \%)$ was of more than 40 years age.

Pre-operative Mean IKDC scores were 43.22+/9.91. Mean pre-operative Lysholm score was $49.07+/-8.93$. IKDC knee examination score was grade C. IKDC scores at 6 months were $92.6+/-$ 1.85 with significant differences ( $p$-value $<0.001$ ). At 6 months mean Lysholm scores were 96+/-3.16 with significant differences ( $p$-value $<0.001)$. At 6 months, all patients had IKDC Grade A score.

Table 2: IKDC subjective knee scores and Lysholm scores

\begin{tabular}{|l|c|c|c|c|}
\hline & $\mathrm{N}$ & Mean & Std. Deviation & Std. Error Mean \\
\hline IKDC & 14 & 43.22 & 9.91 & 2.650 \\
\hline LYSHOLM & 14 & 49.07 & 8.93 & 2.386 \\
\hline
\end{tabular}

\begin{tabular}{|l|c|c|c|c|c|}
\hline & $\mathrm{N}$ & Mean & $\begin{array}{c}\text { Std. } \\
\text { Deviation }\end{array}$ & Std. Error Mean & p- value \\
\hline IKDC6m & 14 & 92.6 & 1.853 & .495 & $<0.001$ \\
\hline LYSHOLM 6m & 14 & 96 & 3.162 & .845 & $<0.001$ \\
\hline
\end{tabular}

Pre-operative 1RM max for Hamstring muscle was 5-10kgs and post-operative 6months 1RM max was 10$15 \mathrm{kgs}$.

Table 3: Pre-operative 1RM max and at 6 months follow up

\begin{tabular}{|l|c|c|c|c|c|}
\hline & $\mathrm{N}$ & Mean & Std. Deviation & minimum & $\max$ \\
\hline 1RM max 0m & 14 & 6.4 & 2.3 & 5 & 10 \\
\hline 1RM max 6m & 14 & 11.4 & 2.3 & 10 & 15 \\
\hline
\end{tabular}

Patients had pre-operative VAS score range 2-6. The mean pre-operative VAS score was 4.35 with standard deviation 1.21. Patients had postoperative 6 months VAS score range 0-3. The mean post-operative 6 months VAS score was 1.07 with standard deviation 1.49. $\mathrm{p}$ value < 0.0001

Table 4: VAS score pre-operative and 6 months follow up

\begin{tabular}{|l|c|c|c|c|}
\hline & N & Mean & Std. Deviation & Std. Error Mean \\
\hline VAS 0m & 14 & 4.35 & 1.21 & .324 \\
\hline VAS 6m & 14 & 1.07 & 1.49 & .368 \\
\hline
\end{tabular}

Intra-operative hamstring graft diameter range was found in between $8.5-9.5 \mathrm{~mm}$ and mean was $9.1 \mathrm{~mm}$. Anterior laxity in the pre-operative period was grade $\mathrm{C}(5-10 \mathrm{~mm})$ and after postoperative 6 months, anterior laxity was grade A $(0-2 \mathrm{~mm})$.None of the patients had laxity. Around 
$50 \%$ patients complained of anterior knee pain but the intensity was significantly decreased compared to pre-operative period. Out of 14 patients, one patient complained of decreased sensation over scar site. Patients had very good functional outcomes in post-operative 6 months follow up as compared pre-operative status.

\section{Discussion}

ACL injuries are usually related to sports activities, and the vast majority of them require surgical reconstruction with a reasonable graft to successfully re-establish the normal functions of the knee joint and to eliminating anterior tibial subluxation. The quadrupled hamstring grafts is an ideal graft for ACL reconstruction. Quadrupled hamstring grafts diameter is $7-8 \mathrm{~mm}$ and due to less graft diameter, there is a more ACL graft failure rate.

The diameter of ACL hamstring graft is directly correlated with graft strength ${ }^{[6]}$. It has been found that graft of larger size behaves close to native ACL in relation to fiber length changes which control the knee laxity in flexion range ${ }^{[7]}$.

It has been found that revision surgery rates are high in hamstring grafts of smaller size. So, new techniques have been developed to increase the size of hamstring graft. In a new technique, the standard 4-strand hamstring graft can be converted into 5- stranded one with the use of 3 equal strands of semitendinosus and 2 strands of gracilis. In five strand hamstring graft usually, graft diameter is $9-10 \mathrm{~mm}$. This extra strand of graft increases the diameter by $1-1.5 \mathrm{~mm}$ and provide more stability, better functional outcomes and the less failure. The present study was aimed at investigating the functional outcome of the 5 strand hamstring grafts.

The age distribution of patients in our study shows that ACL injuries are common in the physically active population group of $20-40$ years. The mean age of patients in our study was 28.78 years. In another Indian study done by Patel et al ${ }^{[8]}$ in 25 patients with quadrupled hamstring graft with biodegradable interference screw found mean age 28.2 years which was similar to the current study. In a retrospective analysis done by Calvo et $\mathrm{al}^{[4]}$ to compare the outcomes of Five-Strand Hamstring Autograft and Quadruple Hamstring Autograft. In this study, they found that mean age in five strand hamstring group was 30.6 years which is similar to our study.

Table-5: Comparison of four-strand and five strand hamstring graft-demographic data and intra-operative graft diameter data

\begin{tabular}{|l|c|c|c|c|}
\hline Study & Type of study & $\begin{array}{c}\text { Patients } \\
\text { 5-strand }\end{array}$ & Mean age (5-strand) & $\begin{array}{c}\text { Average graft diameter } \\
\text { (5-strand) }\end{array}$ \\
\hline Calvo et al.[75] & retro & 37 & 30.6 & $9.2 \mathrm{~mm}$ \\
\hline Current study & pro & 14 & 28.7 & $9.1 \mathrm{~mm}$ \\
\hline
\end{tabular}

More than half of the patients $(57.14 \%)$ were injured during a sporting activity.28.57\% were injured in a road traffic accident. Also, more often than not females are more prone to ACL injuries $^{[9]}$. However, our study doesn't have any female patient. This reflects the lower participation of females in sports and outdoor activities owing to their social obligations.

The present study included patients who presented within one year of injury. It was conducted in a population of predominantly rural background where still indigenous treatment techniques such as native bandaging hold a prominent place in injury management. Indian rural population usually present to modern tertiary healthcare facilities after some time of intentional neglect or after a period of native treatment. We had 2 patients who had at least 1 month of indigenous treatment before approaching our hospital. However, at the time of surgery both patients were optimized to have full knee ROM without any effusion, so that post-operative function is not biased.

In a recent study by Lavery et $\mathrm{al}^{[3]}$, described a 
new technique of making 5- strand hamstring autograft by attaching the extra strand to the suture button loop. This extra strand of 5-HT autograft was expected to increase the diameter of the graft and possibly graft strength also. They used Endo Button for femoral fixation and screws for tibial fixation.

We found significant differences in the IKDC, IKDCE scores and Lysholm scores between preoperative and post-operative period. We found that mean IKDC score pre-operative was 43.22 $(\mathrm{SD}=9.91)$ while post-operative 6 months follow up mean score was $92.6(\mathrm{SD}=1.85)$. This result was similar to the retrospective study done by Calvoetal ${ }^{[4]}$ in which they found mean IKDC score was pre-operative 61.02 and post-operative 96.8 .

We found that Mean Lysholm score pre-operative was $49.07(\mathrm{SD}=8.93)$ while post-operative 6 months follow up Lysholm scores was 96 $(\mathrm{SD}=3.16)$. this result was similar to the retrospective study done by Calvo et $\mathrm{al}^{[4]}$ in which they found pre-operative Lysholm score was 59.1 and post-operative Lysholm score was 97.1 in 6 months post-surgery follow up.

Table 5: Comparison of pre-operative and post-operative IKDC and LYSHOLM scores in five strand hamstring graft

\begin{tabular}{|l|c|c|c|c|}
\hline Study & $\begin{array}{c}\text { Mean IKDC score } \\
\text { pre- operative 5- } \\
\text { strand }\end{array}$ & $\begin{array}{c}\text { Mean IKDC score } \\
\text { post- operative } \\
\text { 5-strand }\end{array}$ & $\begin{array}{c}\text { Mean } \\
\text { LYSHOLM } \\
\text { Score pre- operative } \\
\text { (5-strand) }\end{array}$ & $\begin{array}{c}\text { Mean } \\
\text { LYSHOLM } \\
\text { Score pre- operative } \\
\text { (5-strand) }\end{array}$ \\
\hline Calvo et al.[75] & 61.02 & 96.8 & 59.1 & 97.1 \\
\hline Current study & 43.22 & 92.6 & 49.07 & 96 \\
\hline
\end{tabular}

IKDCE group pre-operative was $\mathrm{C}$ and after postoperative 6 months follow up, it was A. Similar study by Patel et $\mathrm{al}^{[8]}$ on 25 patients, where they reconstructed ACL with help of four-stranded ST$\mathrm{G}$ autograft fixed with bio absorbable interference screw. In this study, they found that the mean Lysholm knee score was 91.2 (range, 63 to 99)and the mean IKDC score was 90.7 (range, 60 to 98) at 6 months follow up after surgery.

In the present study, Patients had pre-operative $1 \mathrm{RM}$ max ranging from $5-10 \mathrm{~kg}$. The mean preoperative $1 \mathrm{RM}$ max was $6.4 \mathrm{~kg}$ with 2.3 standard deviations. Patients had post-operative 6 months $1 \mathrm{RM}$ max ranging from $10-15 \mathrm{~kg}$. The mean postoperative 1RM max was $11.4 \mathrm{~kg}$ with 2.3 standard deviation. The Patients had pre-operative VAS score range 2-6. The mean pre- operative VAS score was 4.35 with standard deviation 1.21 and Patients had post- operative 6 months VAS score range 0-3. The mean post-operative 6 months VAS score was 1.07 with standard deviation 1.49. Similarly, Soon et al ${ }^{[10]}$ study on 76 patient and found no anterior knee pain at rest. A study was done by Spicer et $\mathrm{al}^{[11]}$, on forty- four patients found that almost $89 \%$ patients were asymptomatic or experienced little pain with daily normal activities.

We found that all patient who was in group $\mathrm{C}$ preoperatively where anterior laxity was $6-10 \mathrm{~mm}$ improved to group A post-operatively where the anterior laxity was $0-2 \mathrm{~mm}$. Donor site sensation pre-operatively was normal in all patients and in post-operative 6 months follow up we found that donor site sensation was decreased in 1 patient. Similarly, Soon et al ${ }^{[10]}$, a study on 76 patient, they found that only 3 patients had less sensation at the donor site. In contrast to our study Sgaglione et $\mathrm{al}^{[12]}$ found that $37 \%$ patients had paraesthesia after reconstruction of ACL with semitendinosus tendon. However, it was argued that paraesthesia was because of arthrotomy rather than the tendon harvest.

We found intra-operative hamstring graft diameter range from $8.5-9.5 \mathrm{~mm}$. In 6 patients graft diameter was $9.5 \mathrm{~mm}$, in 6 patients graft diameter was $9 \mathrm{~mm}$ and in 2 patients graft diameter was 
found $8.5 \mathrm{~mm}$. In a retrospective study by Calvo et $\mathrm{al}^{[4]}$ where they compared outcomes of FiveStrand Hamstring Autograft and Quadruple Hamstring Autograft and they found average diameter in five strand hamstring graft was $9.2 \mathrm{~mm}$. In a study by Magnussen et $\mathrm{al}^{[13]}$ on 256 patients who were operated by hamstring autograft found that $7 \%$ of the patient need for a revision surgery at 14 months post-operative follow up. They found that patients with less graft cross sectional area and age were having more failure rate and underwent revision surgery. In patients with graft cross sectional area was more than 8 $\mathrm{mm}$, revision surgery rate was $1.7 \%$ and crosssectional area between $7.5-8 \mathrm{~mm}$ had revision surgery rate of $6.5 \%$, cross-sectional area less than $7 \mathrm{~mm}$ had revision surgery rate of 13.6 .

\section{Conclusion}

To conclude the present study showed that there are good clinical outcomes of five strand hamstring autograft at short-term follow-up.

We found that at 6 months follow up postoperative almost all of our patients regained normal strength without any decrease in donor site sensation. None of them had a complaint of subjective knee laxity. The pain was significantly reduced. Not a single patient required revision surgery due to laxity, this may be because of larger graft diameter of five strand autograft. The clinical outcome scores as measured by IKDC score, Lysholm score were significantly improved at short-term follow up period of 6 months.

We found that pre-operative Mean IKDC scores were 43.22+/-9.91. IKDC scores at 6 months follow up were $92.6+/-1.85$ with significant differences ( $p$ - value $<0.001$ ). We found that preoperative Lysholm score was 59.1 and follow up at 6 months post-operative the Lysholm score was 97.1. We found that Intra-operative hamstring graft diameter range was found in between 8.5$9.5 \mathrm{~mm}$ and mean was $9.1 \mathrm{~mm} 1 \mathrm{RM}$ max for hamstring pre-operative was 5-10 kgs. and after 6 months follow up 1RM max was 10-15 kgs. Patients had pre-operative VAS score range 2-6.
The mean pre-operative VAS score was 4.35 with standard deviation 1.21. Patients had postoperative 6 months VAS score range $0-3$. The mean post-operative 6 months VAS score was 1.07 with standard deviation 1.49 .

\section{Limitations}

There are some limitations to our study. We included only 14 patients in our study. All patients completed 6 months follow-up. The small sample size is the limitation of our study. The short-term follow up is also another limitation. A larger study with longer follow-up could probably shed more light on the long-term outcomes of five strand hamstring autograft.

\section{References}

1. Lee RJ, Ganley TJ. The 5-Strand Hamstring Graft in Anterior Cruciate Ligament Reconstruction. Arthrosc Tech. 2014;20;3(5):e627-31.

2. Prodromos C, Joyce B. Five-Strand Hamstring Anterior Cruciate Ligament Reconstruction: Presentation of a New Technique with Better Stability at 7- to 9Year Follow Up Than 4 Strand. Techniques in Orthopaedics. 2005 Sep 1; 20:192-3.

3. Lavery KP, Rasmussen JF, Dhawan A. Five-strand hamstring autograft for anterior cruciate ligament reconstruction. Arthrosc Tech.2014;3(4):e423-6.

4. Calvo R, Figueroa D, Figueroa F, Vaisman A, Schmidt-Hebbel A, Morales N, et al. Five-Strand Hamstring Autograft Versus Quadruple Hamstring Autograft With Graft Diameters 8.0 Millimeters or More in Anterior Cruciate Ligament Reconstruction: Clinical Outcomes With a Minimum 2-Year Follow-Up. Arthroscopy. 2017May;33(5):1007-13.

5. Tutkus V, Kluonaitis $\mathrm{K}$, Silove $\mathrm{S}$, Tutkuviene J. ACL reconstruction using 5or 6-strand hamstring autograft provides grafte $^{\text {e }}$ diameter bigger than $8 \mathrm{~mm}$. Knee 
Surg Sports TraumatolArthrosc. 2017 Aug7.

6. Hamner DL, Brown $\mathrm{CH}$ Jr, Steiner ME, Hecker AT, Hayes WC. Hamstring tendon grafts for reconstruction of the anterior cruciate ligament: biomechanical evaluation of the use of multiple strands and tensioning techniques. J Bone Joint Surg Am1999;81(4):549-57.

7. Robinson J, Stanford FC, Kendoff D, Stüber V, Pearle AD. Replication of the range of native anterior cruciate ligament fiber length change behavior achieved by different grafts: measurement using computer-assisted navigation. Am J Sports Med 2009;37(7):1406-11.

8. Patel S, Chauhan DV, Juyal A, Maheshwari R, Agrawal A. Evaluation of Arthroscopic Anterior Cruciate Ligament Reconstruction using Hamstring graft. Indian medgazette.2014;10:384-88.

9. Sutton KM, Bullock JM. Anterior cruciate ligament rupture: differences between males and females. J Am Acad Orthop Surg. 2013Jan;21(1):41-50.

10. Soon M, Neo CPC, Mitra AK, Tay BK. Morbidity following anterior cruciate ligament reconstruction using hamstring autograft. Ann Acad Med Singap. 2004;33(2):214-9.

11. Spicer DD, Blagg SE, Unwin AJ, Allum RL. Anterior knee symptoms after fourstrand hamstring tendon anterior cruciate ligament reconstruction. Knee Surg Sports Traumatol Arthrosc.2000;8(5):286-9.

12. Sgaglione NA, Pizzo WD, Fox JM, Friedman MJ. Arthroscopically assisted anterior cruciate ligament reconstruction with the pes anserine tendons: Comparison of results in acute and chronic ligament deficiency. Am J Sports Med. 1993 Mar1;21(2):249-56.

13. Magnussen RA, Lawrence JTR, West RL, Toth AP, Taylor DC, Garrett WE. Graft size and patient age are predictors of early revision after anterior cruciate ligament reconstruction with hamstring autograft. Arthroscopy. 2012;28(4):526-31. 